\title{
Atomic Structure Control of Silica Thin Films on Pt(111)
}

Andrew S Crampton, Claron J. Ridge, Marian David Rötzer, Gregor Zwaschka, Thomas Braun, Valerio D'Elia, Jean-Marie Basset, Florian Frank Schweinberger, Sebastian Günther, and Ueli Heiz J. Phys. Chem. C, Just Accepted Manuscript • DOI: 10.1021/acs.jpcc.5b02667 • Publication Date (Web): 27 May 2015 Downloaded from http://pubs.acs.org on May 31, 2015

\section{Just Accepted}

"Just Accepted" manuscripts have been peer-reviewed and accepted for publication. They are posted online prior to technical editing, formatting for publication and author proofing. The American Chemical Society provides "Just Accepted" as a free service to the research community to expedite the dissemination of scientific material as soon as possible after acceptance. "Just Accepted" manuscripts appear in full in PDF format accompanied by an HTML abstract. "Just Accepted" manuscripts have been fully peer reviewed, but should not be considered the official version of record. They are accessible to all readers and citable by the Digital Object Identifier (DOI®). "Just Accepted" is an optional service offered to authors. Therefore, the "Just Accepted" Web site may not include all articles that will be published in the journal. After a manuscript is technically edited and formatted, it will be removed from the "Just Accepted" Web site and published as an ASAP article. Note that technical editing may introduce minor changes to the manuscript text and/or graphics which could affect content, and all legal disclaimers and ethical guidelines that apply to the journal pertain. ACS cannot be held responsible for errors or consequences arising from the use of information contained in these "Just Accepted" manuscripts. 


\title{
Atomic Structure Control of Silica Thin Films
}

\section{on $\operatorname{Pt}(111)$}

\author{
A.S. Crampton, ${ }^{\dagger, \ddagger}$ C.J. Ridge, ${ }^{\dagger}, \dagger$ M. D. Rötzer, ${ }^{\dagger}$ G. Zwaschka, ${ }^{\dagger}$ T. Braun, ${ }^{\dagger}$ V. \\ D'Elia, ${ }^{\ddagger}$ J.-M. Basset, ${ }^{\ddagger}$ F.F. Schweinberger, ${ }^{* \dagger} \dagger$ S. Günther, ${ }^{\rrbracket}$ and U. Heiz \\ Technische Universität München, Lehrstuhl für Physikalische Chemie, Zentralinstitut für \\ Katalyseforschung und Fakultät für Chemie, Lichtenbergstr. 4, 85748 Garching, Germany, \\ KAUST Catalysis Center (KCC), King Abdullah University of Science and Technology, \\ Thuwal, 23955 Kingdom of Saudi Arabia, and Technische Universität München, Fachgebiet \\ Physikalische Chemie mit Schwerpunkt Katalyse, Zentralinstitut für Katalyseforschung und \\ Fakultät für Chemie, Lichtenbergstr. 4, 85748 Garching, Germany \\ E-mail: florian.schweinberger@tum.de
}

\footnotetext{
${ }^{*}$ To whom correspondence should be addressed

${ }^{\dagger}$ Technische Universität München, Lehrstuhl für Physikalische Chemie, Zentralinstitut für Katalyseforschung und Fakultät für Chemie, Lichtenbergstr. 4, 85748 Garching, Germany

${ }^{\ddagger}$ KAUST Catalysis Center (KCC), King Abdullah University of Science and Technology, Thuwal, 23955 Kingdom of Saudi Arabia

9Technische Universität München, Fachgebiet Physikalische Chemie mit Schwerpunkt Katalyse, Zentralinstitut für Katalyseforschung und Fakultät für Chemie, Lichtenbergstr. 4, 85748 Garching, Germany 


\begin{abstract}
Metal oxide thin films grown on metal single crystals are commonly used to model heterogeneous catalyst supports. The structure and properties of thin silicon dioxide films grown on metal single crystals have only recently been thoroughly characterized and their spectral properties well established. We report the successful growth of a threedimensional, vitreous silicon dioxide thin film on the $\mathrm{Pt}(111)$ surface and reproduce the closed bilayer structure previously reported. The confirmation of the three dimensional nature of the film is unequivocally shown by the infrared absorption band at $1252 \mathrm{~cm}^{-1}$. Temperature programmed desorption was used to show that this three-dimensional thin film covers the $\mathrm{Pt}(111)$ surface to such an extent that its application as a catalyst support for clusters/nanoparticles is possible. The growth of a three-dimensional film was seen to be directly correlated with the amount of oxygen present on the surface after the silicon evaporation process. This excess of oxygen is tentatively attributed to atomic oxygen being generated in the evaporator. The identification of atomic oxygen as a necessary building block for the formation of a three-dimensional thin film opens up new possibilities for thin film growth on metal supports, whereby simply changing the type of oxygen enables thin films with different atomic structures to be synthesized. This is a novel approach to tune the synthesis parameters of thin films to grow a specific structure and expands the options for modeling common amorphous silica supports under ultra high vacuum conditions.
\end{abstract}

Keywords: UPS (He I $\alpha$ ), MIES, TPD, IRRAS, $\mathrm{SiO}_{2}$, CVD. 


\section{Introduction}

Thin metal oxide films have become a standard tool to support model heterogeneous catalysts under ultra high vacuum (UHV) conditions $^{1-3}$, as well as being studied for an assortment of applications in materials science. Silicon dioxide $\left(\mathrm{SiO}_{2}\right)$ is one of the most commonly used supports in heterogeneous catalysis ${ }^{4,5}$, and much progress has been made in growing thin $\mathrm{SiO}_{2}$ films on metal single crystals, as well as revealing the underlying growth mechanisms and structures formed. $\mathrm{Mo}(110), \mathrm{Mo}(112)$ and $\mathrm{Ru}(0001)$ have all been shown to be ideal candidates for the growth of these films and their structural properties have been well documented. ${ }^{6-17}$ From these studies it has been shown that the type of silica film can be solely determined by its infrared vibration band: $\sim 1300 \mathrm{~cm}^{-1}$ for a bilayer, $\sim 1250 \mathrm{~cm}^{-1}$ for a thick, vitreous film, and $\sim 1065$ or $\sim 1135 \mathrm{~cm}^{-1}$ for a monolayer film on $\mathrm{Mo}(112)$ or $\operatorname{Ru}(0001)$, respectively. ${ }^{16} \mathrm{SiO}_{2}$ films have also been successfully grown on $\mathrm{Ni}(111)^{18}, \mathrm{Pd}(100)^{19}$, and $\operatorname{Pd}(111)^{20}$, but have not been characterized to the extent of the aforementioned surfaces. $\mathrm{Pt}(111)$ has only recently emerged as another candidate for growing thin $\mathrm{SiO}_{2}$ films and has been shown to form a closed bilayer structure, similar to the one observed on $\mathrm{Ru}(0001)$, and scanning tunneling microscopy (STM) showed that it is vitreous and does not completely cover the surface. ${ }^{9,16}$

The trend observed for the structure of these thin films was shown to follow two parameters: lattice mismatch and oxygen affinity of the metal support. A greater lattice mismatch results in a non-crystalline thin film, as was shown for the bilayer on $\operatorname{Pt}(111)$ compared to $\mathrm{Ru}(0001)$. Oxygen affinity influences the ability to form Si-O-metal bonds and this is believed to allow for the formation of a monolayer film seen on $\mathrm{Mo}(112)$ and $\mathrm{Ru}(0001) .{ }^{9}$ Both the large lattice mismatch and the low oxygen affinity of $\operatorname{Pt}(111)$ mean that silica has only been grown as a closed bilayer with no Si-O-Pt bond (low oxygen affinity) and in a vitreous state (large lattice mismatch). ${ }^{9,16}$ In this paper we reproduce on $\operatorname{Pt}(111)$ the bilayer previously reported and successfully synthesize a three-dimensional vitreous film. Using Auger electron spectroscopy (AES), metastable impact electron spectroscopy (MIES), ultraviolet 
photoelectron spectroscopy (UPS), and infrared reflection absorption spectroscopy (IRRAS), we show that the atomic structure of the film is determined by the amount of oxygen on the surface after silicon deposition and that the thicker films exhibit similar spectroscopic behavior observed for other thick $\mathrm{SiO}_{2}$ films grown on $\mathrm{Mo}(112)$ and $\mathrm{Ru}(0001)$ while retaining the vitreous nature observed for the bilayer. Lastly, the applicability of a bilayer or threedimensional film as a support for model catalyst systems is also investigated using temperature programmed desorption (TPD). The ability to grow a thin silica film on a Pt(111) surface that completely covers the metal enables the direct comparison between a catalytically active single crystal and supported metal particles using the same experimental instrumentation, i.e. random error arising from the use of two single crystals (e.g. Mo(112) for supported clusters and $\operatorname{Pt}(111)$ as a model single crystal catalyst) can be ruled out. Furthermore, it has been shown that the metal upon which thin films are grown can influence nanoparticle

morphology by a charge transfer mechanism from the thin film/metal interface. ${ }^{21-23}$ The ability to grow thin, closed silica films on $\mathrm{Pt}(111)$, allows for the investigation of these structure-property relationships with regards to to the underlying metal support. The change in work function between $\mathrm{Mo}, \mathrm{Ru}$ and $\mathrm{Pt}$, represents a decisive parameter governing surface charging effects, whose influence on nanoparticle morphology, and hence catalytic activity, can now be investigated. This also represents a corollary to dopants in bulk metal oxides, and these effects can now be modeled by simply changing the metal support. This is an important step to expand the variety of parameters of model heterogeneous catalyst systems under UHV and their comparability to more applied systems.

\section{Experimental}

All experiments were performed in a UHV chamber at a base pressure of $2 \times 10^{-10}$ mbar; details about the setup can be found elsewhere. ${ }^{24}$

Prior to the measurements the Pt(111) crystal (MaTeck, Germany) was cleaned by 
repeated cycles of $\mathrm{Ar}^{+}$sputtering $\left(T=900 \mathrm{~K}, p\left(A r^{+}\right)=5 \times 10^{-6} \mathrm{mbar}, \triangle t=60 \mathrm{~min}, U=\right.$ $1 \mathrm{keV}, I \sim 10 \mu \mathrm{A})$ followed by oxidation $\left(T=650 \mathrm{~K}, p\left(O_{2}\right)=5 \times 10^{-7} \operatorname{mbar}, \triangle t=5 \mathrm{~min}\right)$ and annealing $(T=1300 \mathrm{~K}, \triangle t=1 \mathrm{~min})$; subsequently the single crystal purity was checked by means of AES and MIES/UPS and is in good agreement with the literature.

The $\mathrm{SiO}_{2}$ thin film was prepared by e-beam evaporation (Tectra, Germany) of a silicon rod (99.999\% purity, Alfa-Aesar, Germany) in an oxygen (5.5 purity, AirLiquide, Germany) background pressure $\left(T=400 \mathrm{~K}, p\left(O_{2}\right)=2 \times 10^{-6}\right.$ mbar $)$ onto the $\operatorname{Pt}(111)$ single crystal surface. The flux of the silicon beam was measured using an electrode on the end of the evaporator, with the normal flux being $\sim 10 \mathrm{nA}$ and, where specified, half-flux being $\sim 5 \mathrm{nA}$. The film was then annealed at $1200 \mathrm{~K}$ in a $2 \times 10^{-6}$ mbar oxygen atmosphere before experimental data was acquired, unless otherwise mentioned. A single-shot four minute and ten minute film growth step was performed to synthesize the bilayer and three-dimensional thin film, respectively. The electron emission spectra (EES) were all recorded at $100 \mathrm{~K}$ and further details regarding the spectroscopic setup can be found in our previous publications. ${ }^{25,26}$ The IRRAS experiments were performed at $100 \mathrm{~K}$ (Thermo-Nicolet FT-6700, Thermo-Nicolet MCT detector) and averaged 256 scans at $4 \mathrm{~cm}^{-1}$ resolution. The TPDs (Balzers QMG 430, Lichtenstein) were run with a temperature ramp of $2 \mathrm{~K} / \mathrm{s}$ and the gas dosage was performed with a calibrated molecular beam doser. ${ }^{27}$

\section{Results}

IRRAS spectra taken after four and ten minutes of film growth on $\mathrm{Pt}(111)$ followed by annealing at $1200 \mathrm{~K}$ are shown in figure 1 . The peak at $1288 \mathrm{~cm}^{-1}$ corresponds to Si-O-Si vibrations within a closed bilayer thin film after four minutes of film growth. ${ }^{16}$ After ten minutes of silicon evaporation a peak at $1252 \mathrm{~cm}^{-1}$ with a broad shoulder down to $1100 \mathrm{~cm}^{-1}$ appeared and these are the asymmetric longitudinal phonon vibrations, characteristic for a thick vitreous film. $\mathrm{Ru}(0001)$ also exhibited this exact trend where a bilayer was first observed 
with a peak at $1300 \mathrm{~cm}^{-1}$ and upon further film growth the bilayer peak disappeared and a peak centered at $1257 \mathrm{~cm}^{-1}$ with a broad shoulder down to $1100 \mathrm{~cm}^{-1}$ appeared. ${ }^{15}$ The clear formation of the bilayer after 4 minutes indicates that the film deposition rate is on the order of 0.5 monolayer $/ \mathrm{min}$. The presence of the thick film after 10 minutes would mean a film thickness of 5 atomic layers, which is similar to the thickness of 3-dimensional films grown on $\mathrm{Ru}(0001) .{ }^{15}$ Assuming similar values for the thin films on $\mathrm{Ru}$, the approximate thickness of the 3-dimensional film grown on $\operatorname{Pt}(111)$ is $10 \AA$.

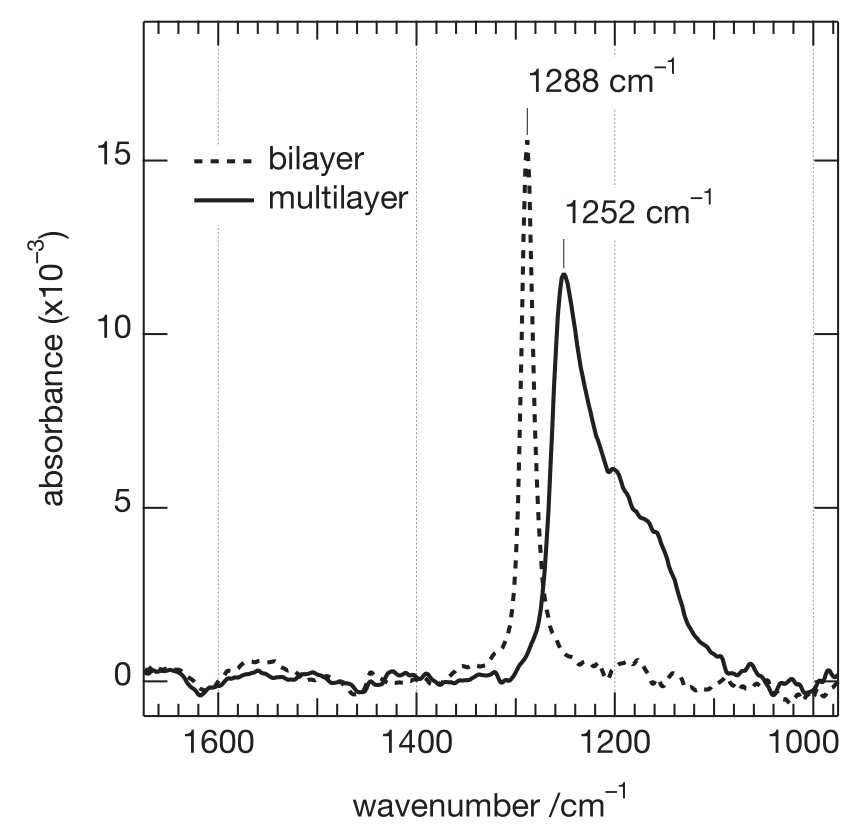

Figure 1: IRRAS spectra for the three-dimensional and bilayer silica film. Each film shows a characteristic peak: bilayer at $1288 \mathrm{~cm}^{-1}$ and the three-dimensional film at $1252 \mathrm{~cm}^{-1}$.

The EES spectra in figure 2 show the $\mathrm{SiO}_{2}$ valence bands after four and ten minutes of film growth each followed by $1200 \mathrm{~K}$ annealing before spectral characterization. The UP spectra have been background corrected by means of a previously introduced method in order to remove secondary electron contributions. ${ }^{25}$ This procedure was not applied to the MIE spectra as the secondary electron contribution was not as significant. After four minutes of film growth a broad peak appeared, centered at 6.4 and $6.7 \mathrm{eV}$ for UPS and MIES, respectively, belonging to the $\mathrm{O}(2 \mathrm{p})$ nonbonding state. Additionally, a MIES peak emerged at $10.7 \mathrm{eV}$ belonging to the Si-O bonding state. After ten minutes of film growth the $\mathrm{O}(2 \mathrm{p})$ peak shifted 
to 6.8 and $7.4 \mathrm{eV}$ for UPS and MIES, respectively, while the Si-O peak appeared at $11.0 \mathrm{eV}$ for UPS and MIES. ${ }^{12}$
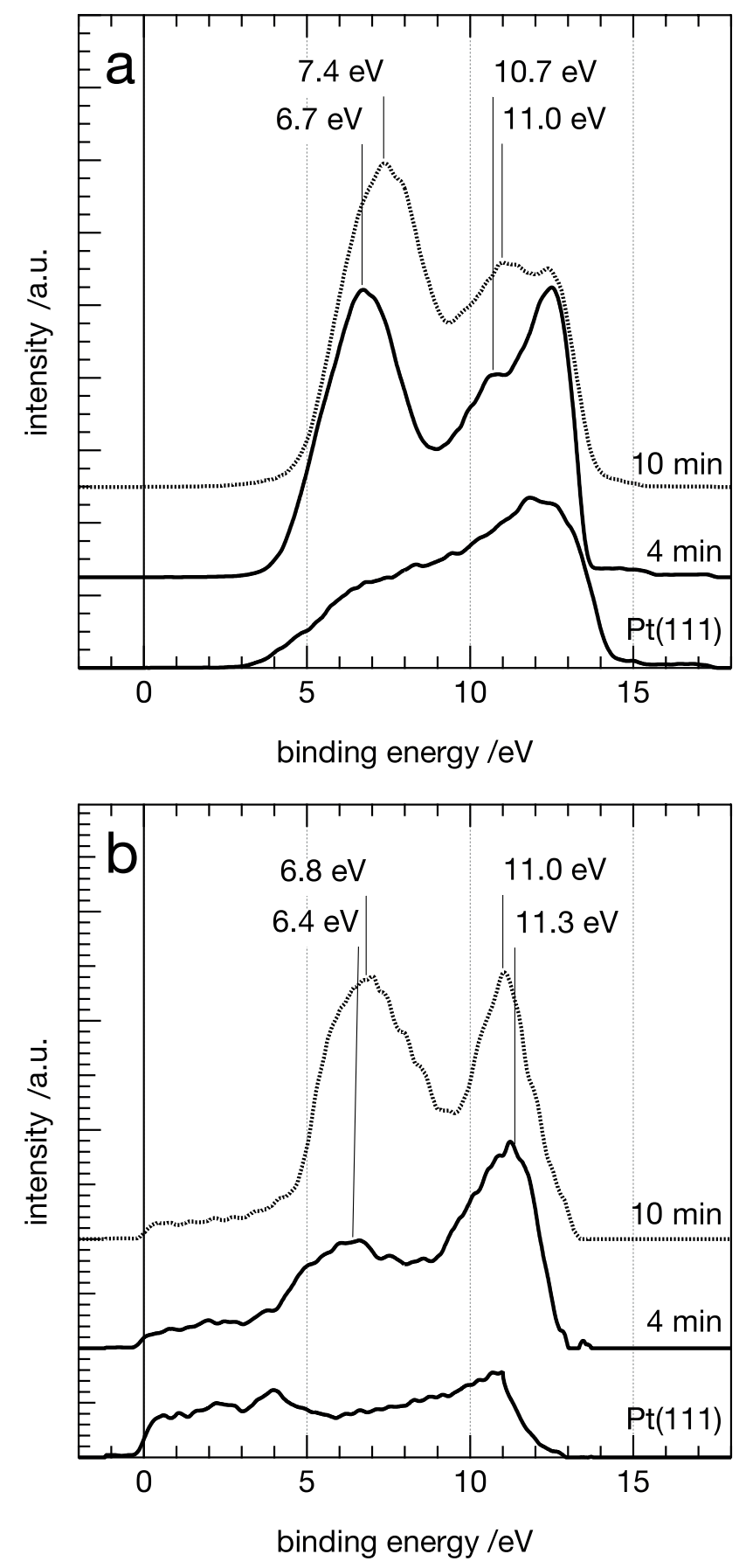

Figure 2: MIE (a) and background corrected UP (b) spectra of the silica thin film at different preparation steps. The bottom spectrum shows the clean $\operatorname{Pt}(111)$ single crystal surface, then after four minutes of film growth with subsequent annealing at $1200 \mathrm{~K}$ and lastly after ten minutes of growth and annealing at $1200 \mathrm{~K}$. The uppermost spectrum can be assigned to the vitreous, three-dimensional $\mathrm{SiO}_{2}$ and the middle spectrum to the bilayer thin film. 
Deuterium TPD spectra were collected from both the three-dimensional and bilayer film can be seen in figure 3. The spectra show that the thick film has no $\mathrm{D}_{2}$ desorption peak, whereas the bilayer shows a small peak centered at $300 \mathrm{~K}$ corresponding to desorption from uncovered $\mathrm{Pt}(111)$.

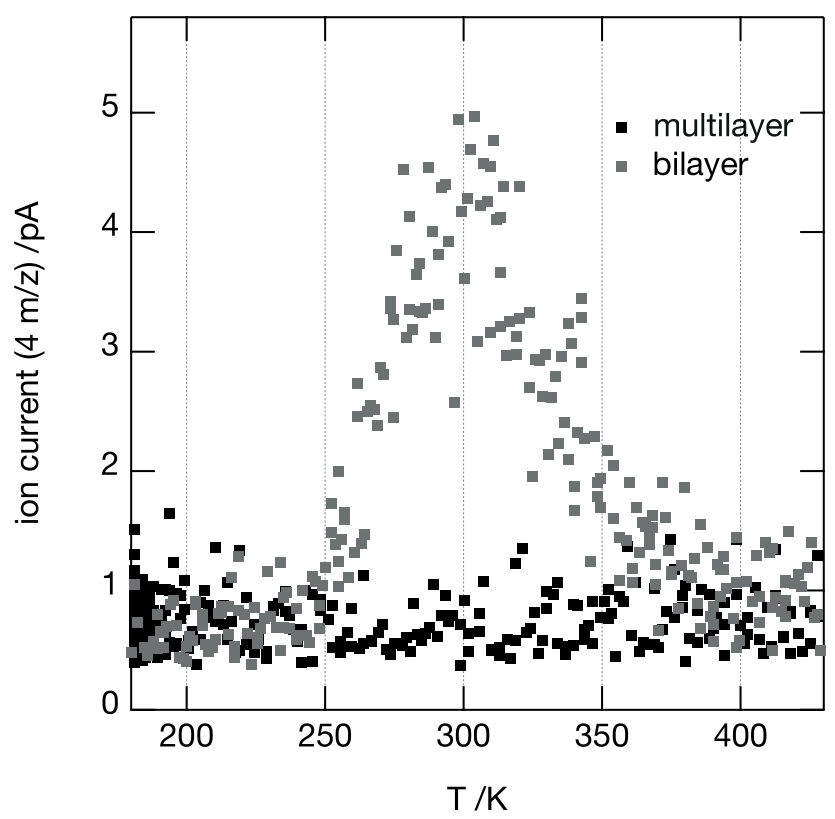

Figure 3: Deuterium TPD spectrum of $0.4 \mathrm{D}_{2}$ /surface atom dosed at $100 \mathrm{~K}$ on the threedimensional and bilayer silica film. 


\section{Discussion}
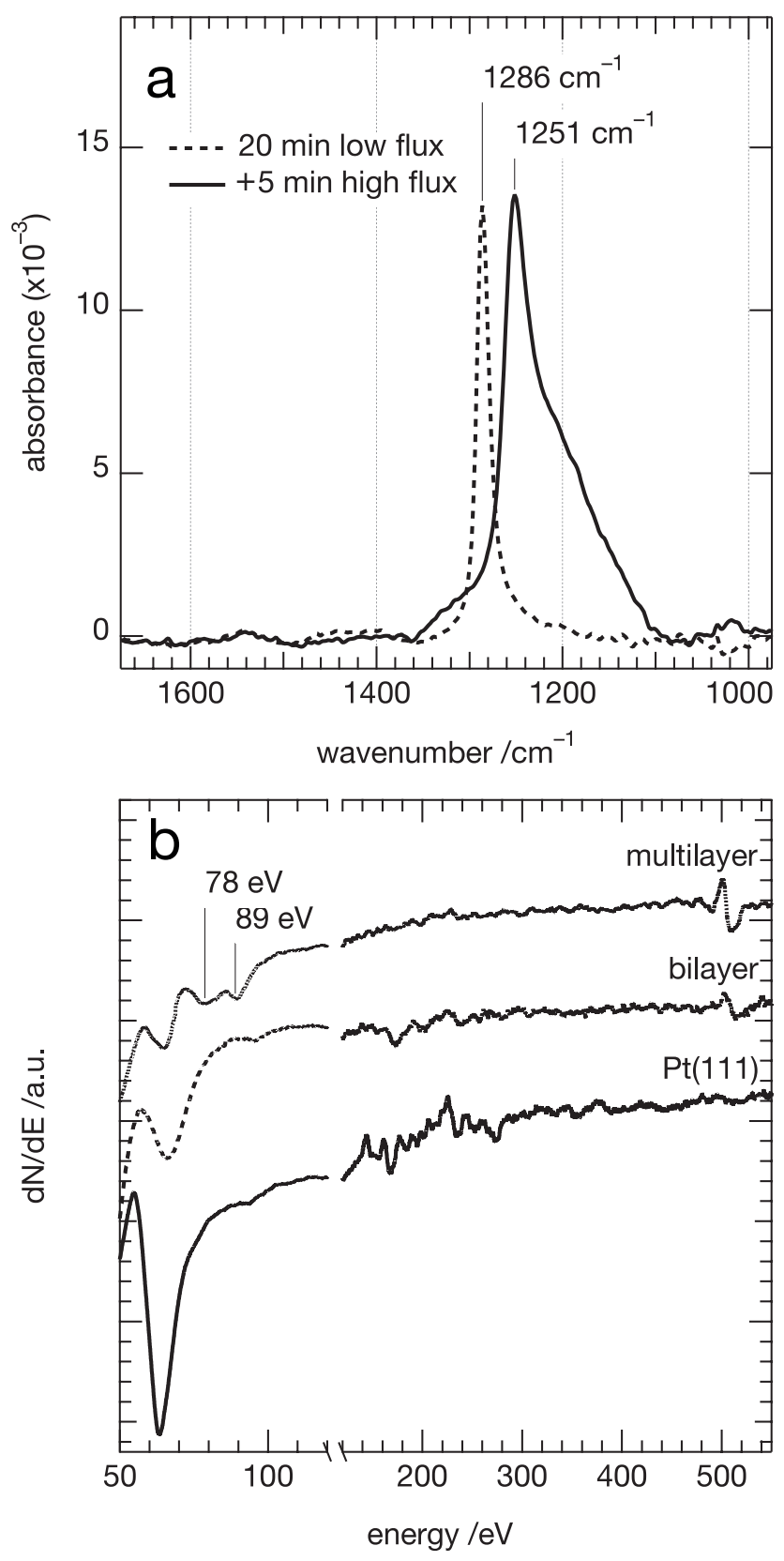

Figure 4: IRRAS spectra (a) after 20 min film growth using half the silicon flux as previously reported, followed by five minutes of normal flux film growth, both after annealing at $1200 \mathrm{~K}$. AES spectra (b) for a clean $\mathrm{Pt}(111)$ surface, the bilayer $\mathrm{SiO}_{2}$ film after 20 minutes of low flux silicon deposition, and the multilayer film after 10 minutes of film growth at normal flux (both without annealing at $1200 \mathrm{~K}$ ), keeping the total amount of silicon deposited constant. The region above $150 \mathrm{eV}$ has been multiplied by a factor of two. 
The results of figure 1 demonstrate that a three-dimensional, vitreous silica film can be grown on $\operatorname{Pt}(111)$. This overcomes the limitations which restricted silica films to exclusively a bilayer structure. ${ }^{9,16}$ The reason for the formation of the three-dimensional film in contrast to previous reports, was identified by varying the film growth parameters. $\mathrm{A} \mathrm{SiO}_{2}$ film was grown for 20 min using half the silicon flux previously used, followed by acquisition of an IR spectrum seen in figure 4a. Even after $20 \mathrm{~min}$ of film growth, only the bilayer formed. On top of this film, five minutes of the normal flux film growth protocol was performed and the three-dimensional film was observed. Auger spectra taken after an identical low flux experiment were compared with those taken after the normal flux experiment (the ten minute standard growth protocol), both seen in figure 4b. Both AES experiments were performed in a way that an equal amount of silicon was evaporated on the $\operatorname{Pt}(111)$ surface. As both spectra were taken before high temperature annealing, both are showing the same surface concentration of silicon. No large elemental silicon peak at $92 \mathrm{eV}$ is visible, in contrast to silicon deposited ${ }^{28}$ on and segregated ${ }^{29}$ from the $\mathrm{Pt}(111)$ surface. This is, however, to be expected in the presence of atomic oxygen, where no elemental silicon peak is observed after oxidizing at $\sim 400 \mathrm{~K}$. Instead, when using molecular oxygen as the oxidizing agent, a very large peak at $92 \mathrm{eV}$ is visible. ${ }^{29}$ The absence of a well defined peak at $92 \mathrm{eV}$ implies that atomic oxygen, likely being generated in the evaporator, is oxidizing the deposited silicon. We identify the oxygen species as atomic oxygen based on the similarity of our Auger spectra to those in Ref. [29]. A direct identification of atomic oxygen is not possible due to the geometry of the evaporator with respect to the mass spectrometer and therefore a definitive assignment is not possible. It is, however, unlikely that ionized oxygen species are responsible due to the potential of $-18 \mathrm{~V}$ applied to the electrode at the end of the evaporator, but excited states of molecular and/or atomic oxygen cannot be ruled out.

The normal flux spectrum shows two peaks at 78 and $89 \mathrm{eV}$, which are known $\mathrm{SiO}_{x}(\mathrm{LVV})$ transitions from $\mathrm{SiO}_{2}$ and $\mathrm{SiO}_{x<2}$, respectively. The low flux spectrum shows only a very small feature at $\sim 93 \mathrm{eV}$ indicating that the nature of silicon deposited under these conditions 
is more varied than with the higher flux, i.e. the degree of oxidation varies from completely unoxidized to fully oxidized which causes the Auger peak to smear out over a wide range of energies, rendering it unresolvable in AES.

The amount of oxygen can be readily quantified from the $\mathrm{O}(\mathrm{KLL})$ Auger peak at $508 \mathrm{eV}$. Comparing the size of the oxygen peak to the Pt transition at $237 \mathrm{eV}$, the amount of oxygen almost doubles when doubling the flux. As both low and normal flux experiments have deposited the same amount of silicon, the only difference between the two surfaces is the amount of oxygen present. As the same background oxygen pressure was used for both experiments, the increase in oxygen must be originating from the increased evaporation rate (more specifically the increased filament current in the evaporator) and the most probable oxygen source which could be affected is atomic oxygen generated in the evaporator.

As $\mathrm{SiO}_{4}$ tetrahedra have been proposed as the structural units for three-dimensional films on $\mathrm{Ru}(0001)^{9}$, the concentration of these types of units during deposition and annealing must be a decisive factor discriminating between formation of purely the bilayer, and formation of three-dimensional $\mathrm{SiO}_{2}$. The $\mathrm{SiO}_{2}(\mathrm{LVV})$ Auger peak at $78 \mathrm{eV}$ clearly shows that the threedimensional growth protocol produces more oxidized silicon which indicates that increasing atomic oxygen has the effect of increasing the surface concentration of fully oxidized silicon species. These species ultimately lead to the formation of a three-dimensional structure that completely covers the metal surface. It is also known that the saturation coverage of atomic oxygen on $\mathrm{Pt}(111)$ is approximately double that from molecular oxygen adsorption and dissociation. ${ }^{30,31}$ This evidences a compound effect, whereby increased atomic oxygen leads to a higher oxygen saturation coverage of open platinum surface domains, which facilitates the formation of fully oxidized silicon species and a complete covering of the metal. This shows that limitations on film growth imposed by a surface's oxygen affinity and adsorption properties can be circumvented by using atomic oxygen while concomitantly changing the atomic structure of the thin film grown.

A second factor governed by the degree of silicon oxidation during deposition is etching 
of the film during annealing at $1200 \mathrm{~K}$ effectively 'dissolving' the metal oxide. ${ }^{32}$ This could also play a factor in the unsuccessful attempts to grow three-dimensional $\mathrm{SiO}_{2}$ on $\mathrm{Pt}(111)$ where a combination of a lower concentration of oxidized silicon and a higher concentration of elemental silicon both act to suppress the formation of three-dimensional $\mathrm{SiO}_{2}$. After annealing our film to $1200 \mathrm{~K}$ all $\mathrm{SiO}_{x<2}$ features disappeared, which we attribute to the desorption of $\mathrm{SiO}$, in agreement with the known desorption above $1200 \mathrm{~K}$ from silicon surfaces. ${ }^{33-35}$

The peak positions from the EES experiments compare well to experiments performed on Mo(112) but do show slight deviations, the most obvious being the $\mathrm{O}(2 \mathrm{p})$ state, which does not split into two well resolved peaks after annealing at high temperatures $(\sim 1100-1200 \mathrm{~K})$. Instead, this peak remains broad and shifts to higher binding energy for the thicker film. The broad nature of the valence band peaks has been attributed to a higher concentration of defect sites $^{36}$ and a lack of crystallinity within the thin film. ${ }^{8}$ The deviation of $0.6 \mathrm{eV}$ between the two spectroscopic methods can be explained by the surface sensitivity of MIES compared to UPS. MIES probes only the uppermost surface layer due to impenetrability of helium atoms into the surface. Thus, the UPS spectra originate from a convolution of the pure surface states seen in MIES and the underlying emission from the bulk, leading to the broader UPS peak and its shoulders on the high binding energy side.

The presence of a single peak centered at $11.0 \mathrm{eV}$, in both the UP spectrum and the MIE spectrum, also corroborates the lack of Si-O-Pt linkages. This is in contrast to EES spectra from $\mathrm{SiO}_{2}$ on $\mathrm{Mo}(112)$ where a shoulder at $10.5 \mathrm{eV}$ on the larger $\mathrm{Si}-\mathrm{O}$ peak at $11.5 \mathrm{eV}$ was observed and attributed to a Si-O-Mo bond. ${ }^{12}$ The presence of only one peak in this binding energy range is to be expected, when $\mathrm{Si}-\mathrm{O}-\mathrm{Pt}$ bonds are absent. As previously mentioned, results on $\mathrm{Pt}(111)$ have shown a distinct lack of crystallinity when compared to $\mathrm{Mo}(112)$ and $\mathrm{Ru}(0001)^{9}$ and our MIES/UPS results show that silica grown on $\mathrm{Pt}(111)$ produces no twin peak $\mathrm{O}(2 \mathrm{p})$ feature corresponding to a crystalline film and no feature belonging to a Si-O-Pt state is observed. 


\section{Conclusion}

In summary, we have reproduced the growth of a bilayer $\mathrm{SiO}_{2}$ thin film on $\mathrm{Pt}(111)$ and observed the expected spectral behavior based on previous reports, including an incomplete covering of the surface which supports STM results ${ }^{9}$. In addition, the growth of a threedimensional vitreous $\mathrm{SiO}_{2}$ film was achieved on the $\mathrm{Pt}(111)$ surface and exhibits the same characteristics as thick $\mathrm{SiO}_{2}$ films produced on $\mathrm{Ru}(0001), \mathrm{Mo}(110)$ and $\mathrm{Mo}(112) .{ }^{10,14,15}$ The confirmation that the film belongs to the three-dimensional category was confirmed with IRRAS where a peak at $1252 \mathrm{~cm}^{-1}$ with a shoulder down to $1100 \mathrm{~cm}^{-1}$ is indicative of a multilayer silica film, in contrast to the sharp bilayer absorption band observed at $1288 \mathrm{~cm}^{-1}$.

The absence of $\mathrm{O}(2 \mathrm{p})$ peak splitting and fine structure within the EES spectra further indicates the lack of crystallinity in both the bilayer and thick silica film. Additionally, no other emission peak was observed that could be attributed to a Si-O-Pt state.

TPD measurements show that the bilayer film is a poor choice as a nanoparticle support for catalytic measurements due to incomplete coverage of the active $\operatorname{Pt}(111)$ surface. The thick film, however, shows that it completely covers the Pt(111) surface and can therefore be applied as a catalyst support for UHV experiments which more closely models supports used for ambient pressure experiments. Catalytic measurements on an active metal single 
crystal as well as from particles supported on a thin film grown on the same single crystal, eliminates random error and allows for the most accurate comparison of measurements from the pure single crystal and the supported metal particles. The ability to grow the same thin film on three different metals (Mo, Ru and $\mathrm{Pt}$ ) also allows for a systematic study of their influence on clusters/nanoparticles. The difference in work function between the metals is one interesting parameter which could lead to different particle morphologies by attenuating or enhancing the degree of charge transfer from the thin film/metal interface, while also providing a technique to model dopant effects in bulk metal oxides.

The exclusive growth of a bilayer film was observed when half the silicon flux compared to the normal procedure was used. By increasing the flux it was observed that the amount of oxygen present after deposition doubles even though the deposited amount of silicon, and oxygen background pressure, remain the same. This excess oxygen is tentatively attributed to atomic oxygen being generated by the silicon evaporator. Atomic oxygen would overcome the limitation imposed by the low oxygen affinity of $\mathrm{Pt}(111)$ and allows for a higher oxygen coverage on the surface during silicon evaporation compared to molecular oxygen. This leads to the formation of more fully oxidized silicon species needed for three-dimensional film growth and a complete covering of the surface. Excess elemental silicon deposited on the bilayer, and multilayer film is oxidized to volatile $\mathrm{SiO}$ when annealing the sample to $1200 \mathrm{~K}$, which etches the film. Since in this case the multilayer $\mathrm{SiO}_{2}$ film is also etched, the ability to grow three-dimensional films is dependent on the more oxidized silicon suppressing the etching along with the concomitant increase in the concentration of the requisite building blocks for a three-dimensional film. The identification of atomic oxygen as the discriminating factor between two atomic structures of silica thin films grown on the same metal support has, to our knowledge, never been demonstrated before. This represents an important parameter that can in principle be investigated for the control of atomic structure of any metal oxide thin film on any metal support. 


\section{Acknowledgements}

C.J.R. and F.F.S. thank Prof. Hans-Joachim Freund and Dr. Shamil Shaikhutdinov for their hospitality during our stay at the FHI and their insights into the preparation and characterization of silica thin films. We acknowledge financial support from the DFG through the Nanosystems Initiative Munich (NIM) (F.F.S., C.J.R., M.D.R., A.S.C. and U.H.) and the Project He 3454/9-2 (F.F.S. and U.H.).

\section{References}

(1) Heiz, U.; Sherwood, R.; Cox, D. M.; Kaldor, A.; Yates, J. T. J. Phys. Chem. 1995, 99, $8730-8735$.

(2) Heiz, U.; Sanchez, A.; Abbet, S.; Schneider, W.-D. J. Am. Chem. Soc. 1999, 121, $3214-3217$.

(3) Sanchez, A.; Abbet, S.; Heiz, U.; Schneider, W.-D.; Häkkinen, H.; Barnett, R. N.; Landman, U. J. Phys. Chem. A 1999, 103, 9573-9578.

(4) Basset, J.-M., Psaro, R., Roberto, D., Ugo, R., Eds. Modern Surface Organometallic Chemistry; Wiley-VCH Verlag GmbH \& Co. KGaA, 2009.

(5) Ertl, G.; Knözinger, H.; Schüth, F.; Weitkamp, J. Handbook of Heterogeneous Catalysis, 2nd ed.; Wiley-VCH, 2008.

(6) Löffler, D.; Uhlrich, J. J.; Baron, M.; Yang, B.; Yu, X.; Lichtenstein, L.; Heinke, L.; Büchner, C.; Heyde, M.; Shaikhutdinov, S.; et al., Phys. Rev. Lett. 2010, 105, 146104.

(7) Schroeder, T.; Adelt, M.; Richter, B.; Naschitzki, M.; Bäumer, M.; Freund, H.-J. Surf. Rev. Lett. 2000, 7, 7-14.

(8) Schroeder, T.; Giorgi, J. B.; Bäumer, M.; Freund, H.-J. Phys. Rev. B 2002, 66, 165422. 
(9) Shaikhutdinov, S.; Freund, H.-J. Adv. Mater. 2013, 25, 49-67.

(10) Stacchiola, D. J.; Baron, M.; Kaya, S.; Weissenrieder, J.; Shaikhutdinov, S.; Freund, H.-J. Appl. Phys. Lett. 2008, 92, 011911.

(11) Weissenrieder, J.; Kaya, S.; Lu, J.-L.; Gao, H.-J.; Shaikhutdinov, S.; Freund, H.-J.; Sierka, M.; Todorova, T. K.; Sauer, J. Phys. Rev. Lett. 2005, 95, 076103.

(12) Wendt, S.; Ozensoy, E.; Wei, T.; Frerichs, M.; Cai, Y.; Chen, M. S.; Goodman, D. W. Phys. Rev. B 2005, 72, 115409.

(13) Włodarczyk, R.; Sierka, M.; Sauer, J.; Löffler, D.; Uhlrich, J. J.; Yu, X.; Yang, B.; Groot, I. M. N.; Shaikhutdinov, S.; Freund, H.-J. Phys. Rev. B 2012, 85, 085403.

(14) Xu, X.; Goodman, D. W. Surf. Sci. 1993, 282, 323-332.

(15) Yang, B.; Kaden, W. E.; Yu, X.; Boscoboinik, J. A.; Martynova, Y.; Lichtenstein, L.; Heyde, M.; Sterrer, M.; Włodarczyk, R.; Sierka, M.; et al., Phys. Chem. Chem. Phys. 2012, 14, 11344-11351.

(16) Yu, X.; Yang, B.; Boscoboinik, J. A.; Shaikhutdinov, S.; Freund, H.-J. Appl. Phys. Lett. 2012, 100, 151608 .

(17) He, J.-W.; Xu, X.; Corneille, J. S.; Goodman, D. W. Surf. Sci. 1992, 279, 119-126.

(18) Kundu, M.; Murata, Y. Appl. Phys. Lett. 2002, 80, 1921-1923.

(19) Zhang, Z.; Jiang, Z.; Yao, Y.; Tan, D.; Fu, Q.; Bao, X. Thin Solid Films 2008, 516, $3741-3746$.

(20) Kershner, D. C.; Medlin, J. W. Surf. Sci. 2008, 602, 786-794.

(21) Sterrer, M.; Risse, T.; Heyde, M.; Rust, H.-P.; Freund, H.-J. Phys. Rev. Lett. 2007, 98, 206103. 
(22) Risse, T.; Shaikhutdinov, S.; Nilius, N.; Sterrer, M.; Freund, H.-J. Acc. Chem. Res. 2008, 41, 949-956.

(23) Sauer, J.; Freund, H.-J. Catal. Lett. 2014, 145, 109-125.

(24) Heiz, U.; Vanolli, F.; Trento, L.; Schneider, W.-D. Rev. Sci. Inst. 1997, 68, 1986-1994.

(25) Schweinberger, F. F.; Crampton, A. S.; Zimmermann, T.; Kwon, G.; Ridge, C. J.; Günther, S.; Heiz, U. Surf. Sci. 2013, 609, 18-29.

(26) Spirkl, F. M.; Kunz, S.; Schweinberger, F. F.; Farnbacher, A. N.; Schröter, R.; Heiz, U. Rev. Sci. Inst. 2012, 83, 013114.

(27) Bozack, M. J.; Muehlhoff, L.; J. N. Russel, J.; Choyke, W. J.; Yates, J. J. Vac. Sci. Tech. A. 1987, 5, 1-8.

(28) Niehus, H.; Comsa, G. Surf. Sci. 1981, 102, L14-L20.

(29) Bonzel, H. P.; Franken, A. M.; Pirug, G. Surf. Sci. 1981, 104, 625-642.

(30) Gland, J. L. Surf. Sci. 1980, 93, 487-514.

(31) Parker, D. H.; Bartram, M. E.; Koel, B. E. Surf. Sci. 1989, 217, 489-510.

(32) Leroy, F.; Saito, Y.; Cheynis, F.; Bussmann, E.; Pierre-Louis, O.; Müller, P. Phys. Rev. B 2014, 89, 235406.

(33) Engel, T. Surf. Sci. Rep. 1993, 18, 93-144.

(34) Lander, J. J.; Morrison, J. J. Appl. Phys. 1962, 33, 2089-2092.

(35) Walkup, R. E.; Raider, S. I. Appl. Phys. Lett. 1988, 53, 888-890.

(36) Kim, Y. D.; Wei, T.; Goodman, D. W. Langmuir 2003, 19, 354-357. 


\section{Table of Contents Image}

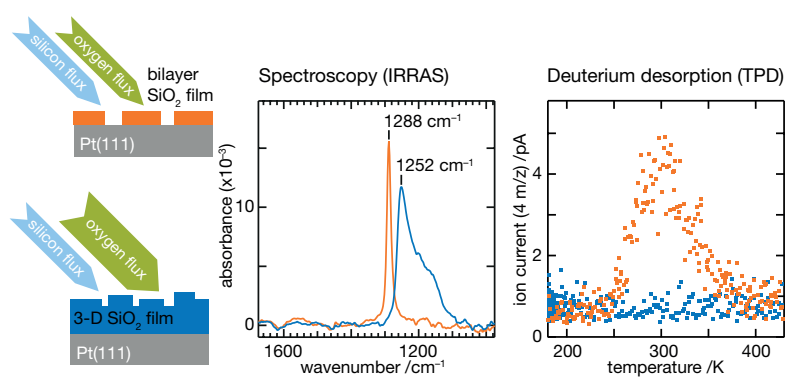

16

17

18

19

20

21

22

23

24

25

26

27

28

29

30

31

32

33

34

35

36

37

38

39

40

41

42

43

44

45

46

47

48

49

50

51

52

53

54

55

56

57

58

59

60 